\title{
Role of Al and Ti doping in modulating electrical properties of BIVOX system
}

\author{
Diptimayee TRIPATHY ${ }^{a,}$, Amarjyoti SAIKIA $^{a}$, \\ Gyati Tachang $\mathrm{TADO}^{a}$, Arvind PANDEY ${ }^{a, b}$ \\ ${ }^{a}$ Department of Physics, North Eastern Regional Institute of Science and Technology, \\ Nirjuli 791109, Arunachal Pradesh, India \\ ${ }^{b}$ Department of Applied Sciences and Humanities, National Institute of Foundry and \\ Forge Technology, Hatia, Ranchi 834003, Jharkhand, India
}

Received: January 25, 2019; Revised: March 12, 2019; Accepted: March 22, 2019

(C) The Author(s) 2019.

\begin{abstract}
The doubly-doped bismuth vanadate with $\mathrm{Al}$ and $\mathrm{Ti}$ having formula unit, $\mathrm{Bi}_{2} \mathrm{~V}_{1-x} \mathrm{Al}_{x / 2} \mathrm{Ti}_{x / 2} \mathrm{O}_{5.5-\delta}(0.10 \leqslant x \leqslant 0.25)$ was synthesized. The specimens were characterized by scanning electron microscopy (SEM), X-ray diffraction (XRD), Fourier transform infrared (FT-IR), differential scanning calorimetric (DSC), UV-Vis, and electrochemical impedance spectroscopy (EIS) for their structural, thermal, optical, and electrical studies. Influence of both dopant cations (Al and Ti) was observed in the gradual stabilization of the tetragonal phase of $\mathrm{Bi}_{2} \mathrm{VO}_{5.5-\delta}$ with dopant amount. A non-uniform grain growth phenomenon was observed up to $x=0.175$, with dopant addition. UV-Vis study revealed the comparatively higher order of oxide ion vacancies for the composition $x=0.175$. Impedance spectroscopy measurements indicate a significant decrease of both the grain $\left(R_{\mathrm{g}}\right)$ and grain boundary resistances $\left(R_{\mathrm{gb}}\right)$ with the rise in temperature and the overall resistance is found to be dominated by the grain interior contribution. Enhancement of ionic conductivity was found in all the compositions in the intermediate temperature range as compared to the parent compound, and the single Al-doped system and the highest value were obtained for $x=0.175$.
\end{abstract}

Keywords: ionic conductivity; doping; phase transition; grain growth

\section{Introduction}

$\mathrm{Bi}_{2} \mathrm{O}_{3}$-based systems exhibit good oxygen-ion conductivity [1] at intermediate temperatures and are significant from application point of view due to a variety of properties like dielectric and ferroelectric behavior [2], catalytic activity $[3,4]$, and photo electrochemical properties [5]. Among $\mathrm{Bi}_{2} \mathrm{O}_{3}$-based systems, bismuth

\footnotetext{
* Corresponding author.

E-mail: tripathydiptimayee@gmail.com
}

vanadate, $\mathrm{Bi}_{2} \mathrm{VO}_{5.5-\delta}$ (where $\delta$ denotes the oxygen-ion vacancy) surfaced in the late eighties is of immense importance because of its visibly good ionic conductivity values at relatively low temperature viz. $0.2 \mathrm{~S} \cdot \mathrm{cm}^{-1}$ at $\sim 600{ }^{\circ} \mathrm{C}$ [6]. However, the problem with this compound is of multiple phase transitions (i.e., $\alpha \leftrightarrow \beta$ and $\beta \leftrightarrow \gamma$ between 420 and $450{ }^{\circ} \mathrm{C}$ and between 540 and $560{ }^{\circ} \mathrm{C}$, respectively) and the highest conductivity is found in tetragonal polymorph known as $\gamma$-polymorph or phase [6,7]. Therefore, stabilization of this phase at room temperature is essential. The 
successful approach for the stabilization of this high temperature-high conducting disordered phase through partial substitution of vanadium by copper was first reported by Abraham et al. [8] in 1990. In one of the doped compound, BICUVOX.10, remarkable high conductivity was found in the temperature range of $227-427{ }^{\circ} \mathrm{C}$. For instance, the conductivity of this compound at $237{ }^{\circ} \mathrm{C}$ was $\sim 10^{-3} \mathrm{~S} \cdot \mathrm{cm}^{-1}$, which is two order higher compared to that of the parent compound. This work leads way to a new group of solid electrolyte termed as bismuth metal vanadium oxide (BIMEVOX), which can be formulated as $\mathrm{Bi}_{4} \mathrm{~V}_{2-x} \mathrm{Me}_{x} \mathrm{O}_{11-\delta}$ or $\mathrm{Bi}_{2} \mathrm{~V}_{1-x} \mathrm{Me}_{x} \mathrm{O}_{5.5-\delta}$ in which $\mathrm{V}^{\mathrm{V}}$ is partially substituted with isovalent and/or aliovalent metal dopants for suppression of reversible polymorphic transitions [9] and room temperature stabilization of the $\gamma$-form. Due to perovskite related crystal structure, BIMEVOXes can accommodate a large concentration of mobile oxygen vacancies that are accountable for the rapid oxygen-ion conduction leading to the higher ionic conductivity than the parent compound. Typical examples include $\mathrm{Cu}, \mathrm{Co}$, $\mathrm{Ni}$, and $\mathrm{Ti}$ doped BIMEVOXes having ionic conductivity values as high as $\sim 10^{-3} \mathrm{~S} \cdot \mathrm{cm}^{-1}$ at $300{ }^{\circ} \mathrm{C}$ $[8,10-14]$. This high ionic conductivity in the intermediate temperature range compared to other fluorite and perovskite-type electrolytes make BIMEVOXes as potential electrolytes viable for low temperature operation. Furthermore, in order to obtain improved ionic conducting properties, BIMEVOX group has also been explored as a different system, i.e., BIMEME*VOX [13-17] by double substitution at both $\mathrm{Bi} / \mathrm{V}$ and/or only V-sites.

It is well known that in oxygen-ion conductor, the enhancement of ionic conductivity very well depends on the appropriate doping. Depending on the nature and concentration of suitable ME-dopant cations, the properties of parent compounds get modified; oxide ion vacancies are created, and disorder and oxygen participation in the ionic transportation increase [18-20].

For this work, we have selected two aliovalent dopant cations: $\mathrm{Al}^{\mathrm{III}}$ and $\mathrm{Ti}^{\mathrm{IV}}$ for partial substitution of $\mathrm{V}$ in the parent compound. As far as single doped BIME ${ }^{\mathrm{III}} \mathrm{VOX}$ system is concerned, it has been found from various previous reports that $\mathrm{Al}-$ doped $\mathrm{Bi}_{2} \mathrm{VO}_{5.5-\delta}$ exhibits ionic conductivity value in the range of $10^{-5} \mathrm{~S} \cdot \mathrm{cm}^{-1}$ at $300{ }^{\circ} \mathrm{C}$ [21-23] and in $\mathrm{BIME}^{\mathrm{IV}}$ VOX system, BITI ${ }^{\mathrm{IV}}$ VOX is the best regarding high ionic conductivity $[13,14]$. Hence, the prospect of the current work is to synthesize $\mathrm{BIAl}^{\mathrm{III}} \mathrm{TI}^{\mathrm{IV}}$ VOX series by varying dopants amount and to study the role of the combination of $\mathrm{Al}^{\mathrm{III}}$ and $\mathrm{Ti}^{\mathrm{IV}}$ as substituent (at V-site) on crystal structure and ionic conductivity of the parent bismuth vanadate.

\section{Materials and methods}

\section{1 Sample preparation}

The conventional solid-state reaction technique was used to prepare the polycrystalline ceramic samples with formula unit $\mathrm{Bi}_{2} \mathrm{~V}_{1-x} \mathrm{Al}_{x / 2} \mathrm{Ti}_{x / 2} \mathrm{O}_{5.5-\delta}(0.10 \leqslant x \leqslant$ 0.25 ), from high purity analytical reagent grade chemicals: $\mathrm{Bi}_{2} \mathrm{O}_{3}$ (LOBA CHEMIE, purity: 99\%), $\mathrm{V}_{2} \mathrm{O}_{5}$ (LOBA CHEMIE, purity: $99 \%$ ), $\mathrm{Al}_{2} \mathrm{O}_{3}$ (SIGMAALDRICH, purity: 99.5\%), and $\mathrm{TiO}_{2}$ (SIGMAALDRICH, purity: 99.7\%). An appropriate amount of constituents oxide was mixed in ethanol and acetone $(1: 1)$ media in an agate mortar. Then the mixture was ground for $10 \mathrm{~h}$ to maintain homogeneity and then heated at $650{ }^{\circ} \mathrm{C}$ for $15 \mathrm{~h}$. The second heat treatment was done at $750{ }^{\circ} \mathrm{C}$ again for $15 \mathrm{~h}$ after an intermediate grinding. Next, $5 \mathrm{wt} \%$ polyvinyl butyral binder (PVB) was added to the ground powders and then pressed at 5 $\mathrm{t}$ into cylindrical pellets of diameter $12 \mathrm{~mm}$ and thickness 1-2 mm. Further, these pellets were sintered at $800{ }^{\circ} \mathrm{C}$ for $10 \mathrm{~h}$ followed by furnace cooling.

\section{2 Experimental techniques}

\subsubsection{Structural characterization}

For structural characterization, the XRD patterns of all studied specimens after calcinations, as well as sintering, were recorded at room temperature using a RIGAKU ULTIMA IV X-ray diffractometer employing $\mathrm{Cu} \mathrm{K \alpha}$ radiation $(\lambda=1.54059 \AA)$. The measurements were performed in the $2 \theta$ range from $10^{\circ}$ to $80^{\circ}$ with a step width of $0.005^{\circ}$. The scan speed was kept $0.35\left(^{\circ}\right) / \mathrm{min}$. The variation in the crystal structure with dopant concentration and phase analysis were carried out using Match-3 [24] software. Lattice parameters were determined through the Rietveld refinement technique by considering $\mathrm{Bi}_{2} \mathrm{~V}_{0.8} \mathrm{Ge}_{0.2} \mathrm{O}_{5.4}[25]$ and $\mathrm{Bi}_{4} \mathrm{~V}_{1.7} \mathrm{Co}_{0.3} \mathrm{O}_{10.547}$ [26] as the starting models in "FullProf' Rietveld program.

The surface morphology study of the sintered samples was performed through a scanning electron microscope (JSM IT300, JEOL, Japan).

The Fourier transform infrared (FT-IR) spectra of the synthesized specimens were recorded at room temperature in the wave number region of 4000$400 \mathrm{~cm}^{-1}$ by using Impact 410 (NICOLET, USA) 
spectrometer in transmittance mode.

To analyze the phase stabilized at room temperature and also the phase transitions with temperature of all specimens, differential scanning calorimetric (DSC) measurements were performed by STA 449 F3$\mathrm{NETZSCH}$ at the heating rate of $5^{\circ} \mathrm{C} / \mathrm{min}$ in an argon atmosphere.

The UV-Vis absorption spectra of the powder samples were measured at room temperature using a UV-2450, SHIMADZU spectrometer in the wavelength range of 200-900 nm.

\subsubsection{Electrical characterization}

The electrical properties of all synthesized samples were studied by electrochemical impedance spectroscopy (EIS) technique. High purity conducting gold paste (SILTECH, Bangalore) was used as an electrode. The impedance spectra were measured between room temperature and $650{ }^{\circ} \mathrm{C}$ over heating and cooling cycles in the air over the frequency range of $4 \mathrm{~Hz}$ to $8 \mathrm{MHz}$ using HIOKI-LCR TESTER IM3536. The procedure described in Ref. [13] was followed to obtain the real impedance of the samples.

\section{Results and discussion}

\section{1 XRD analysis}

Figure 1 shows the XRD patterns of all prepared samples of $\mathrm{Bi}_{2} \mathrm{~V}_{1-x} \mathrm{Al}_{x / 2} \mathrm{Ti}_{x / 2} \mathrm{O}_{5.5-\delta}(0.10 \leqslant x \leqslant 0.25)$ in the $2 \theta$ range from $20^{\circ}$ to $60^{\circ}$. Figure 1(a) shows the diffraction pattern of specimens calcined at $650{ }^{\circ} \mathrm{C}$ in which impurity peak (shown by ${ }^{*}$ ) of $\mathrm{BiVO}_{4}$ (secondary phase) [17] has been observed for all compositions which has gradually become prominent with an increase in dopant concentration. The X-ray diffractograms of specimens after calcination at $750{ }^{\circ} \mathrm{C}$ and sintering at $800{ }^{\circ} \mathrm{C}$ are shown in Figs. 1(b) and 1(c), respectively, in which, for $x=0.25$, the compound with the highest dopant concentration, the impurity peak of the second phase remains even after the repetitive heat treatments. However, for $x \leqslant 0.2$, the disappearance of the same impurity peak implies monophase compounds without any secondary phase after the heat treatment at $750{ }^{\circ} \mathrm{C}$ [27]. Hence, for $x=0.25$, the presence of impurity traces as observed in SEM and impurity peak of secondary phase as observed in XRD analysis suggest the solubility limit in this double doped system is $<0.25$. For $x=0.15$, a clear peak splitting (shown in the inset of Fig. 1) was observed at $2 \theta \approx 32^{\circ}$ at the initial stage, i.e., after first calcinations at $650{ }^{\circ} \mathrm{C}$, indicating the presence of orthorhombic phase, which later gets converged partially after second heat treatment at $750{ }^{\circ} \mathrm{C}$ implying tetragonal phase formation started taking place beyond the temperature of $650{ }^{\circ} \mathrm{C}$. Finally after sintering, a deformed peak was observed that indicates the presence of both orthorhombic and tetragonal phase. Hence to verify the phase, the diffraction patterns of all specimens were fitted with both tetragonal and orthorhombic crystal structures and presented in Table 1. As per result obtained for 0.15 , the orthorhombic and tetragonal symmetry were found to be $40.4 \%$ and $59.6 \%$, respectively. For the specimen with the lowest dopant substitution, i.e., $x=0.1$, the presence of doublets (splitted peaks) at $2 \theta \approx 32.001^{\circ}$ and $2 \theta \approx 32.255^{\circ}$ indexed as (020) and (200), respectively, and along with this a singlet at $2 \theta \approx 46.070^{\circ}$ indexed as (220) clearly indicate the presence of $\beta$-orthorhombic phase. Further, for higher dopant substitution, i.e., $x \geqslant 0.175$, it could be noted that in XRD pattern, the splitted peaks at $2 \theta \approx 32^{\circ}$ converged into a singlet indexed as (110) indicating the existence of tetragonal phase (space group $I 4 / \mathrm{m} \mathrm{mm}$ ) [14]. Moreover, according to the fitting result, for $x=0.10$, it has been found that the specimen is predominantly orthorhombic. For higher substitution level, all specimens were predominantly in the tetragonal phase suggesting eventual tetragonal phase stabilization at room temperature with dopants addition.

From the phase analysis, it has been found that in our double doped system, the lower limit of dopants concentration required for close proximity to complete stabilization of the tetragonal phase at room temperature is $x \geqslant 0.175$. Interestingly, for the single doped $\mathrm{Bi}_{2} \mathrm{~V}_{1-x} \mathrm{Al}^{\mathrm{III}}{ }_{x} \mathrm{O}_{5.5-\delta}$ system, the lower limit is $x=$ 0.1 [21-23], and for the $\mathrm{Bi}_{2} \mathrm{~V}_{1-x} \mathrm{Ti}^{\mathrm{IV}}{ }_{x} \mathrm{O}_{5.5-\delta}$ system, it is $x=0.125$ [14]. This reflects the combined effect of both dopant cations in the stabilization of the tetragonal phase.

The maximum intensity peak of all studied sintered specimens at $2 \theta \approx 28.5^{\circ}$ is shown in Fig. 1(d). Particularly for the compositions, with the tragonal phase at room temperature, a steady shift towards lower $2 \theta$, has been observed. This shifting of peak position indicates the lattice expansion due to the substitution of $\mathrm{V}$ by $\mathrm{Al}$ and $\mathrm{Ti}$ in the initial structure of the parent compound [28].

The fitted Rietveld refined XRD patterns of the present system are displayed in Fig. 1(e). The unit cell parameters of all prepared samples obtained through 

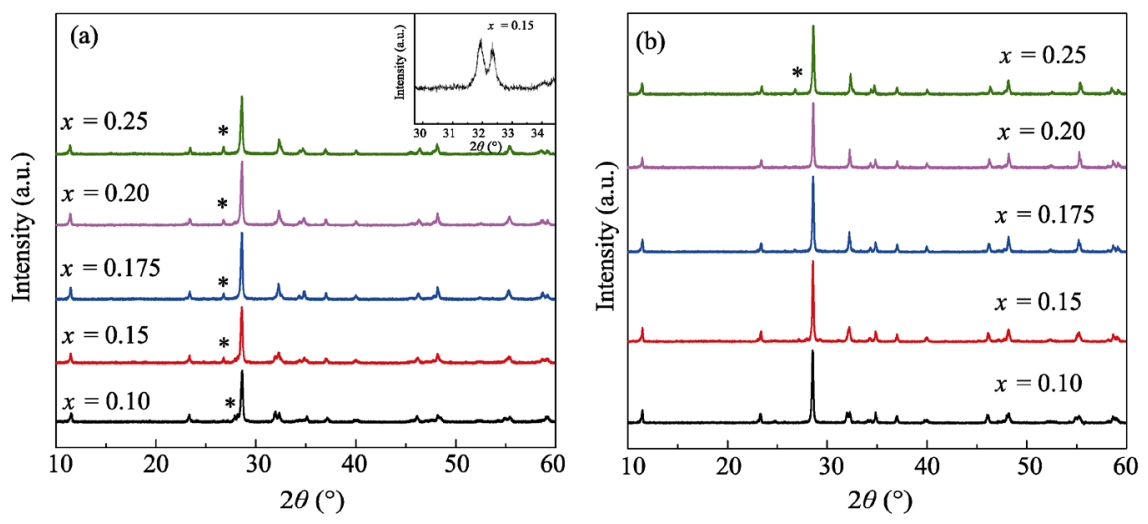
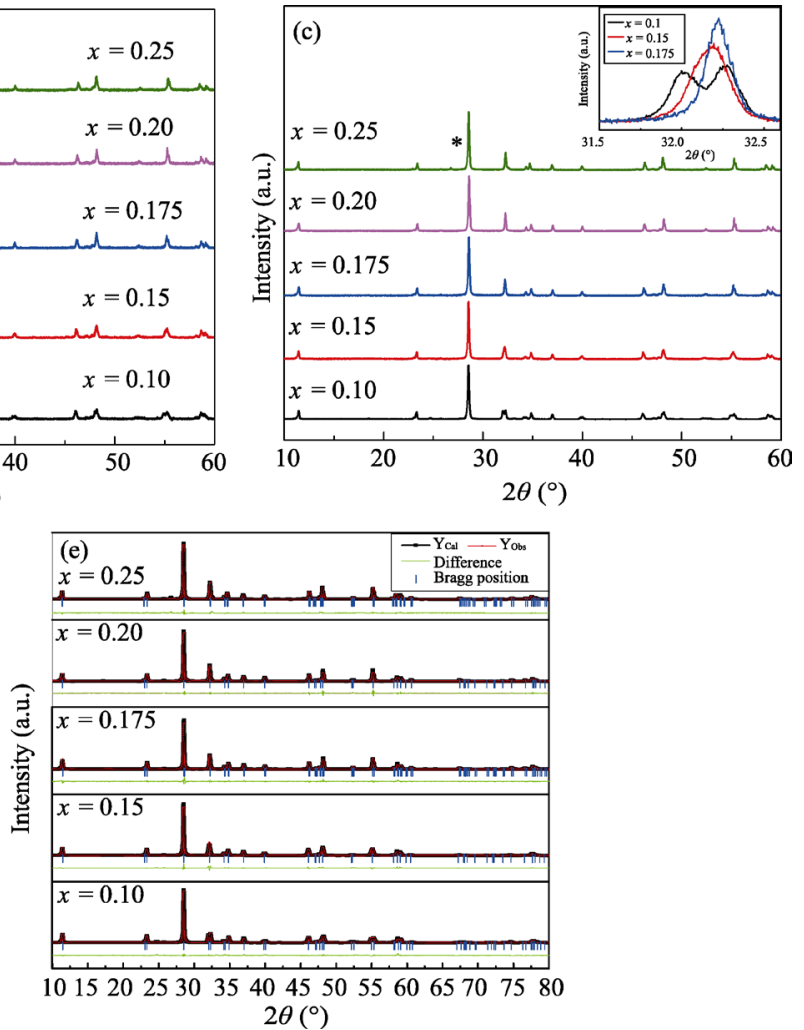

Fig. 1 XRD patterns of the $\mathrm{Bi}_{2} \mathrm{~V}_{1-x} \mathrm{Al}_{x / 2} \mathrm{Ti}_{x / 2} \mathrm{O}_{5.5-\delta}(0.10 \leqslant x \leqslant 0.25)$ specimens after (a) calcination at $650{ }^{\circ} \mathrm{C}$, (b) 2 nd calcination at $750{ }^{\circ} \mathrm{C}$, (c) sintering at $800{ }^{\circ} \mathrm{C}$, (d) the maximum intensity peak at $\sim 28.5^{\circ}$, and (e) fitting with Rietveld refinement sintered at $800{ }^{\circ} \mathrm{C}$.

Table 1 Percentage of orthorhombic and tetragonal phases with variation of dopant concentration

\begin{tabular}{ccc}
\hline$x$ & Orthorhombic symmetry (\%) & Tetragonal symmetry (\%) \\
\hline 0.10 & 73.9 & 26.1 \\
0.15 & 40.4 & 59.6 \\
0.175 & 18.1 & 81.9 \\
0.20 & 10.6 & 89.4 \\
0.25 & 5.1 & 94.9 \\
\hline
\end{tabular}

Rietveld analysis have been given in Table 2. According to the relation $a_{\beta}=\sqrt{2} a_{\gamma}$, the tetragonal $a$-parameters have been presented in mean orthorhombic dimensions. Generally, as observed in other BIMEVOXes, when the host cation $\mathrm{V}^{\mathrm{V}}$ is partially substituted with larger cation dopants $\mathrm{ME}$ in $\mathrm{Bi}_{2} \mathrm{VO}_{5.5}$ lattice structure, the $c$-parameter increases. Therefore, the observed increase in $c$-parameter with increasing $x$ can be correlated with the larger effective ionic radius of $\mathrm{Ti}^{\mathrm{IV}} 0.605 \AA$ as compared to $\mathrm{V}^{\mathrm{V}}(0.54 \AA)$

Unlike $c$-parameter, the variation of the basal parameter with $x$ values depends on the nature of dopant cation [29]. As can be noticed from Table 2, there is a remarkable decrease in $a$-parameter of $x=$
0.10 as compared to $x=0$. However, the decrease in $b$-parameter is marginal. Similarly, in composition with the tetragonal structure, the basal $a$-parameter was found to decrease marginally with the increase of $x$. A similar trend was found here for the present double doped system as reported in the single doped BITI $^{\mathrm{IV}}$ VOX system that the basal parameters variation correlates with oxygen loss in the basal plane [13, $14,30]$. Furthermore, the increase in the volume of all doped compositions than $x=0$ is due to lattice expansion in the initial structure.

\section{2 SEM}

The SEM micrographs of $x=0.10,0.175$, and 0.25 specimens are shown in Figs. 2(a)-2(c). A typical comparison of microstructure concerning substitution level shows finely developed grains and better grain to grain connection up to $x=0.175$. Besides, an insignificant amount of impurities traces have been observed for $0.10 \leqslant x \leqslant 0.20$. However, for $x=$ 0.25 (specimen with higher dopants level), considerable impurities traces have been observed which may be due to doping beyond solubility limit. Non-uniform 
Table 2 Phase and lattice parameters (Rietveld refined) of the $\mathrm{Bi}_{2} \mathrm{~V}_{1-x} \mathrm{Al}_{x / 2} \mathrm{Ti}_{x / 2} \mathrm{O}_{5.5-\delta}(0.10 \leqslant x \leqslant 0.250)$ compounds

\begin{tabular}{ccccccccc}
\hline$x$ & $a(\AA)$ & $b(\AA)$ & $c(\AA)$ & $\mathrm{V}\left(\AA^{3}\right)$ & Phase & $R_{\mathrm{P}}(\%)$ & $R_{\mathrm{WP}}(\%)$ & $R_{\mathrm{E}}(\%)$ \\
\hline 0.10 & $5.5399(4)$ & $5.5827(6)$ & $15.4151(5)$ & 476.75 & $\beta$ & 5.16 & 7.53 & 4.79 \\
$0.15^{*}$ & $5.5514(4)$ & $5.5799(3)$ & $15.4411(4)$ & 478.31 & $\beta$ & 5.61 & 7.98 & 5.02 \\
$0.15^{*}$ & $5.5636(4)$ & - & $15.4463(8)$ & 478.12 & $\gamma$ & 5.50 & 7.59 & 4.81 \\
0.175 & $5.5528(7)$ & - & $15.4540(4)$ & 476.50 & $\gamma$ & 5.46 & 8.07 & 4.86 \\
0.20 & $5.5516(2)$ & - & $15.5162(3)$ & 478.21 & $\gamma$ & 4.39 & 6.67 & 4.76 \\
0.25 & $5.5453(8)$ & - & $15.5631(3)$ & 478.57 & $\gamma$ & 6.71 & 9.50 & 4.71 \\
\hline
\end{tabular}

* Lattice parameters refined in both orthorhombic and tetragonal crystal symmetry; estimated standard deviations of unit cell parameters are given in parenthesis.
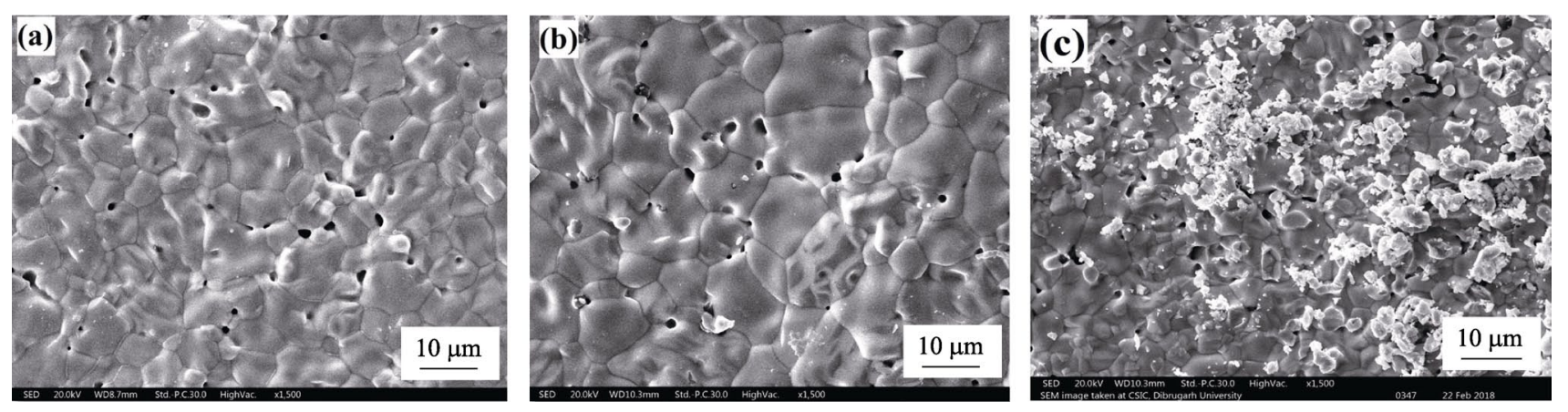

Fig. 2 SEM Micrographs of (a) $x=0.10$, (b) $x=0.175$, and (c) $x=0.25$ of $\mathrm{Bi}_{2} \mathrm{~V}_{1-x} \mathrm{Al}_{x / 2} \mathrm{Ti}_{x / 2} \mathrm{O}_{5.5-\delta}$.

grains have been observed in all compositions, and the average grain size was found to be $5.15,7.24,10.18$, 4.56 , and $3.86 \mu \mathrm{m}$ for $x=0.10,0.15,0.175,0.20$, and 0.25 , respectively. This shows a substantial increase in grain size with increased substitution level till $x=$ 0.175 and further substitution results in comparatively smaller grains. Moreover, the presence of larger grains $(18.24 \mu \mathrm{m})$ along with smaller ones $(4.4 \mu \mathrm{m})$ in $x=$ 0.175 indicates the phenomena of non-uniform grain growth in this compound. Thus, $x=0.175$ may be considered as the optimum dopant amount that assists in better sintering and favours grain growth.

\section{3 FT-IR}

The FT-IR spectra of all prepared compositions are shown in Fig. 3. The characteristics of absorption bands of BIMEVOX are exhibited in all the spectra. Table 3 illustrates the respective band positions: $449-463 \mathrm{~cm}^{-1}$ for $\vartheta(\mathrm{Bi}-\mathrm{O})$ ascribes the vibration of $\mathrm{Bi}-\mathrm{O}$ in bismuth layers, $516-529 \mathrm{~cm}^{-1}$ for $\delta_{\text {as }}$ $(\mathrm{O}-\mathrm{V}-\mathrm{O})$ ascribes the deformation in vanadate layers, $723-764 \mathrm{~cm}^{-1}$ for $\vartheta_{\mathrm{s}}(\mathrm{V}-\mathrm{O})$ is due to symmetric stretching, and $816-829 \mathrm{~cm}^{-1}$ for $\vartheta_{\text {as }}(\mathrm{V}-\mathrm{O})$ is due to asymmetric stretching [31,32].

For $x=0.10$, both $\vartheta_{\mathrm{s}}(\mathrm{V}-\mathrm{O})$ and $\vartheta_{\text {as }}(\mathrm{V}-\mathrm{O})$ bands are well defined indicating the ordered crystal structure of the compound. However, for $x=0.15$, broadening of the $\vartheta_{\mathrm{s}}(\mathrm{V}-\mathrm{O})$ band has been observed implying

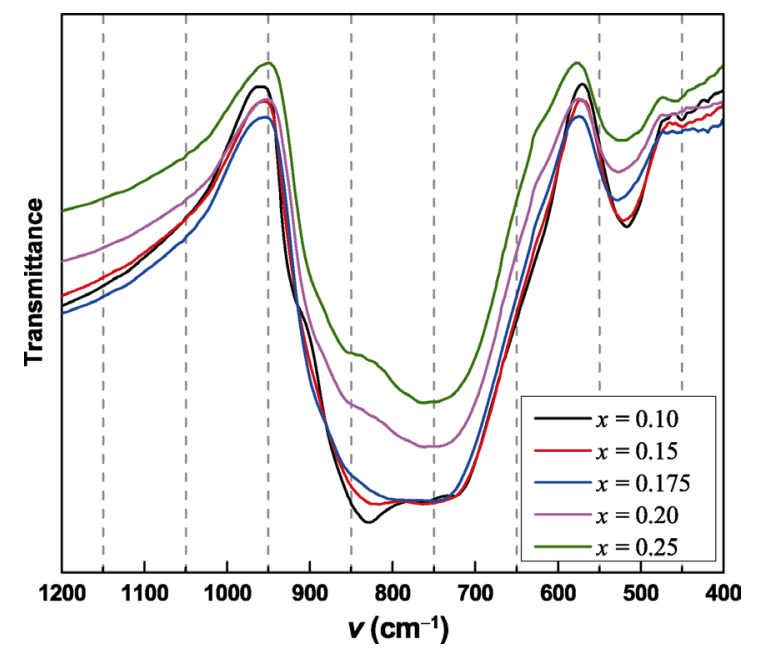

Fig. 3 FT-IR spectra of $\mathrm{Bi}_{2} \mathrm{~V}_{1-x} \mathrm{Al}_{x / 2} \mathrm{Ti}_{x / 2} \mathrm{O}_{5.5-\delta}(0.10 \leqslant$ $x \leqslant 0.25)$.

Table 3 Characteristics bands of BIMEVOX materials from FT-IR spectra

\begin{tabular}{cccccc}
\hline$x$ & $\begin{array}{c}\vartheta(\mathrm{Bi}-\mathrm{O}) \\
\left(\mathrm{cm}^{-1}\right)\end{array}$ & $\begin{array}{c}\boldsymbol{\delta}_{\text {as }}(\mathrm{O}-\mathrm{V}-\mathrm{O}) \\
\left(\mathrm{cm}^{-1}\right)\end{array}$ & $\begin{array}{c}\vartheta_{\mathrm{s}}(\mathrm{VO}) \\
\left(\mathrm{cm}^{-1}\right)\end{array}$ & $\begin{array}{c}\vartheta_{\text {as }}(\mathrm{V}-\mathrm{O}) \\
\left(\mathrm{cm}^{-1}\right)\end{array}$ & $\begin{array}{c}\vartheta(\mathrm{Ti}-\mathrm{O}) / \\
(\mathrm{Al}-\mathrm{O}) \\
\left(\mathrm{cm}^{-1}\right)\end{array}$ \\
\hline 0.10 & 450.54 & 516.73 & 723.11 & 828.16 & - \\
0.15 & 449.01 & 520.84 & 738.23 & 816.06 & - \\
0.175 & 455.36 & 528.39 & 747.97 & - & - \\
0.20 & 456.32 & 526.99 & 761.05 & - & 855.00 \\
0.25 & 462.43 & 522.94 & 763.13 & - & 856.02 \\
\hline
\end{tabular}


beginning of disorder in the crystal structure. Further, with increasing substitution $(0.175 \leqslant x \leqslant 0.25)$, broadening of the $\vartheta_{\mathrm{s}}(\mathrm{V}-\mathrm{O})$ band has been observed. As a result, for $x \geqslant 0.175$, the $\vartheta_{\mathrm{s}}(\mathrm{V}-\mathrm{O})$ band almost disappears in the spectra and absence of this band (Table 3) suggests the high degree of crystallographic disordering, hence can be correlated with the stabilization of the tetragonal structure in these compositions [32]. Moreover, it can be noticed that the fine structure present in $x=0.10$ vanishes gradually with dopant amount signifying the gradual stabilization of tetragonal phase at room temperature with addition of dopants concentration as observed in XRD analysis (Section 3.2). For $x=0.20$ and 0.25, the band at $\sim 855.00$ and $\sim 856.02 \mathrm{~cm}^{-1}$, respectively, could be correlated with the presence of an additional $v(\mathrm{Ti} / \mathrm{Al}-\mathrm{O})$ interaction [33].

\section{4 DSC}

The DSC thermograms of all prepared compositions along with parent compound $\left(\mathrm{Bi}_{2} \mathrm{VO}_{5.5-\delta}\right)$ are illustrated in Fig. 4. In the DSC curve of $\mathrm{Bi}_{2} \mathrm{VO}_{5.5-\delta}$, the presence of two endothermic peaks at 445 and $540{ }^{\circ} \mathrm{C}$ indicate the phase transition of $\alpha \rightarrow \beta$ and $\beta \rightarrow \gamma$, respectively. For $x=0.1$, the single and sharp endothermic peak observed at $421{ }^{\circ} \mathrm{C}$ is the indication of $\beta \rightarrow \gamma$ phase transition that implies stabilization of $\beta$-phase at room temperature in this composition. Again in DSC plot of $x=0.15$, a shallow and small endothermic peak has been observed. This observed peak broadening and decrease in peak intensity with the addition of dopant indicates the lower rate of phase transformation of $\beta \rightarrow \gamma$ may be due to the presence of both tetragonal and orthorhombic phase in this composition at room

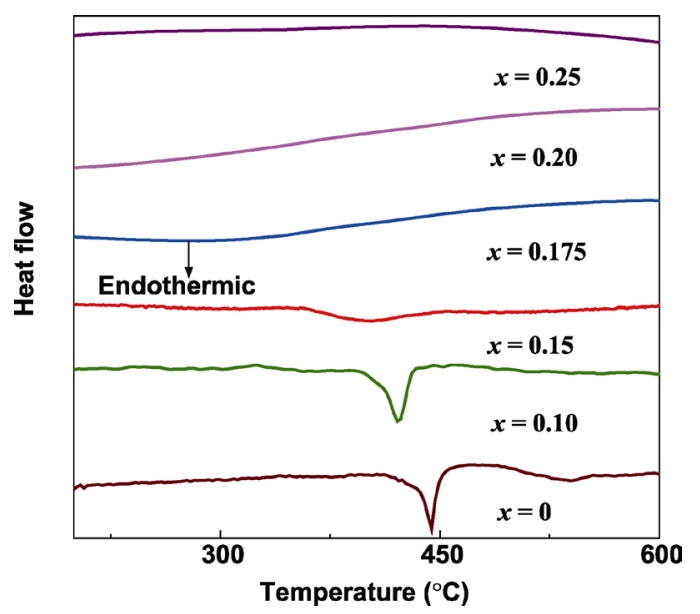

Fig. 4 DSC plots of $\mathrm{Bi}_{2} \mathrm{~V}_{1-x} \mathrm{Al}_{x / 2} \mathrm{Ti}_{x / 2} \mathrm{O}_{5.5-\delta}(0 \leqslant x \leqslant 0.25)$. temperature (Section 3.2). Further, as can be observed in the DSC spectra of $x \geqslant 0.175$, there is no endothermic peak, indicating suppression of phase transition and room temperature stabilization of the tetragonal phase for higher dopant levels. In fact, for $x=0.175$, the dominance of the tetragonal phase overshadows the orthorhombic phase; however, still a very slow transition is noticeable. A typical result shows, shifting of $\beta \rightarrow \gamma$ phase transition peak towards lower temperature side for $0 \leqslant x \leqslant 0.15$ reflects that increasing dopant level tends to decrease the transformation temperature and also shows gradual room temperature stabilization of tetragonal phase. Thus, the XRD, FT-IR, and DSC results are in confirmation with each other.

\section{5 UV-Vis}

According to the equation proposed by Tauc, Davis, and Mott [34-36]:

$$
(h v \alpha)^{1 / n}=A\left(h v-E_{\mathrm{g}}\right)
$$

where $h$ denotes the Planck's constant, $v$ denotes the frequency of vibration, $\alpha$ is for absorption coefficient, $A$ and $E_{\mathrm{g}}$ are proportionality constants which depend upon transition probability and band gap, respectively. The exponent $n$ is an index whose value characterizes the optical absorption process. $n=1 / 2$ and $n=2$ denote direct allowed and indirect allowed transitions, respectively, while $n=3 / 2$ and $n=3$ are for direct forbidden and indirect forbidden transitions, respectively [37]. Further, the obtained diffuse reflectance spectra have been converted into Kubelka-Munk function by introducing the quantity $F(\mathrm{R} \infty)$ (proportional to $\alpha$ ). Thus, Eq. (1) can be rewritten as

$$
(h v F(\mathrm{R} \infty))^{1 / n}=A\left(h v-E_{\mathrm{g}}\right)
$$

Jiang et al. [38] have studied the energy band structure of $\mathrm{Bi}_{2} \mathrm{VO}_{5.5}$ and reported it as a direct band gap semiconductor. Thus, keeping $n=1 / 2$ and rewriting Eq. (2), we obtain

$$
(h v F(\mathrm{R} \infty))^{2}=A\left(h v-E_{\mathrm{g}}\right)
$$

The direct band gap $\left(E_{\mathrm{g}}\right)$ of all the prepared samples along with parent compound was obtained by plotting $(h v F(\mathrm{R} \infty))^{2}$ vs. $h v(1239.7 / \lambda \mathrm{nm})$ and then extrapolating the linear portion of the graph to $X$-axis as shown in Fig. 5 and tabulated in Table 4. For the parent compound, the direct band gap obtained was found to be $2.18 \mathrm{eV}$, which is in good agreement with the previously reported results $[38,39]$. It has been observed that doping of $\mathrm{Al}$ and $\mathrm{Ti}$ at $\mathrm{V}$-site results in the blue shift 


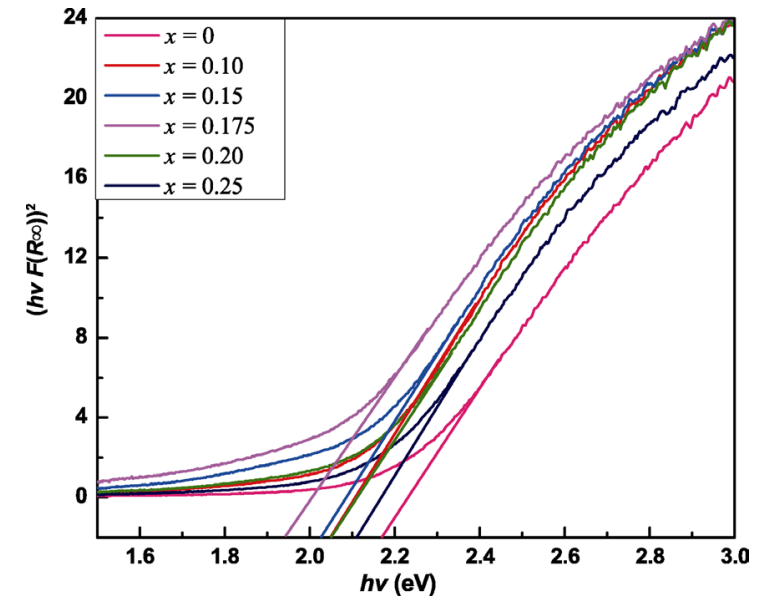

Fig. 5 UV-Vis spectra of $\mathrm{Bi}_{2} \mathrm{~V}_{1-x} \mathrm{Al}_{x / 2} \mathrm{Ti}_{x / 2} \mathrm{O}_{5.5-\delta}(0 \leqslant x$ $\leqslant 0.25)$.

Table 4 Direct band gap of the $\mathrm{Bi}_{2} \mathrm{~V}_{1-x} \mathrm{Al}_{x / 2} \mathrm{Ti}_{x / 2} \mathrm{O}_{5.5-\delta}$ $(0 \leqslant x \leqslant 0.25)$ compounds

\begin{tabular}{ccccccc}
\hline$x$ & 0 & 0.10 & 0.15 & 0.175 & 0.20 & 0.25 \\
\hline$E_{\mathrm{g}}(\mathrm{eV})$ & 2.18 & 2.05 & 2.02 & 1.95 & 2.05 & 2.11 \\
\hline
\end{tabular}

of direct band gap of all the doped samples. Kaur et al. [37] have studied the Til ${ }^{\mathrm{III}}$-doped BIVOX system and have correlated the smaller band gap of the material with the higher conductivity due to optimization of the oxygen vacancies concentration located on equatorial lines of the perovskite layers $\left(\mathrm{VO}_{3.5}\right)^{2-}$. Similarly, in the present system, the observed lowest value of $E_{\mathrm{g}}$ for the composition $x=0.175$ (even compared to parent compound) can be correlated to the presence of comparatively higher order of oxide ion vacancies than other prepared compositions.

\section{6 AC impedance studies}

Mostly for conducting ceramics, the impedance data are presented in Nyquist plots ( $Z^{\prime \prime}$ vs. $\left.Z^{\prime}\right)$. The impedance spectra of $\mathrm{Bi}_{2} \mathrm{~V}_{1-x} \mathrm{Al}_{x / 2} \mathrm{Ti}_{x / 2} \mathrm{O}_{5.5-\delta}(0.10 \leqslant$ $x \leqslant 0.25$ ) at $200{ }^{\circ} \mathrm{C}$ and of $x=0.175$ at different selected temperatures $\left(200-300{ }^{\circ} \mathrm{C}\right)$ are presented in Figs. 6 and 7, respectively, in which, the presence of the second semicircle can be observed but is not much distinct. The Nyquist plots are also characterized by depressed type semicircles with center lying below the real axis. This reflects a non-Debye type of relaxation mechanism in these materials [40]. In general, the different regions of the sample can be characterized by means of parallel RC elements [41]. Hence, for the interpretation of data, the complex plots of $x=0.175$ were fitted with the help of EIS spectrum analyzer

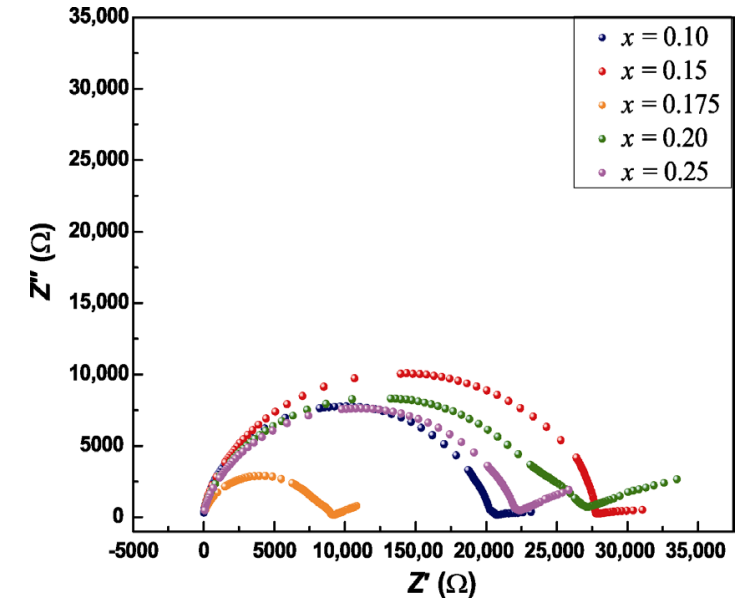

Fig. 6 Complex impedance plane plots of $\mathrm{Bi}_{2} \mathrm{~V}_{1-x} \mathrm{Al}_{x / 2} \mathrm{Ti}_{x / 2} \mathrm{O}_{5.5-\delta}(0.10 \leqslant x \leqslant 0.25)$ at $200{ }^{\circ} \mathrm{C}$.
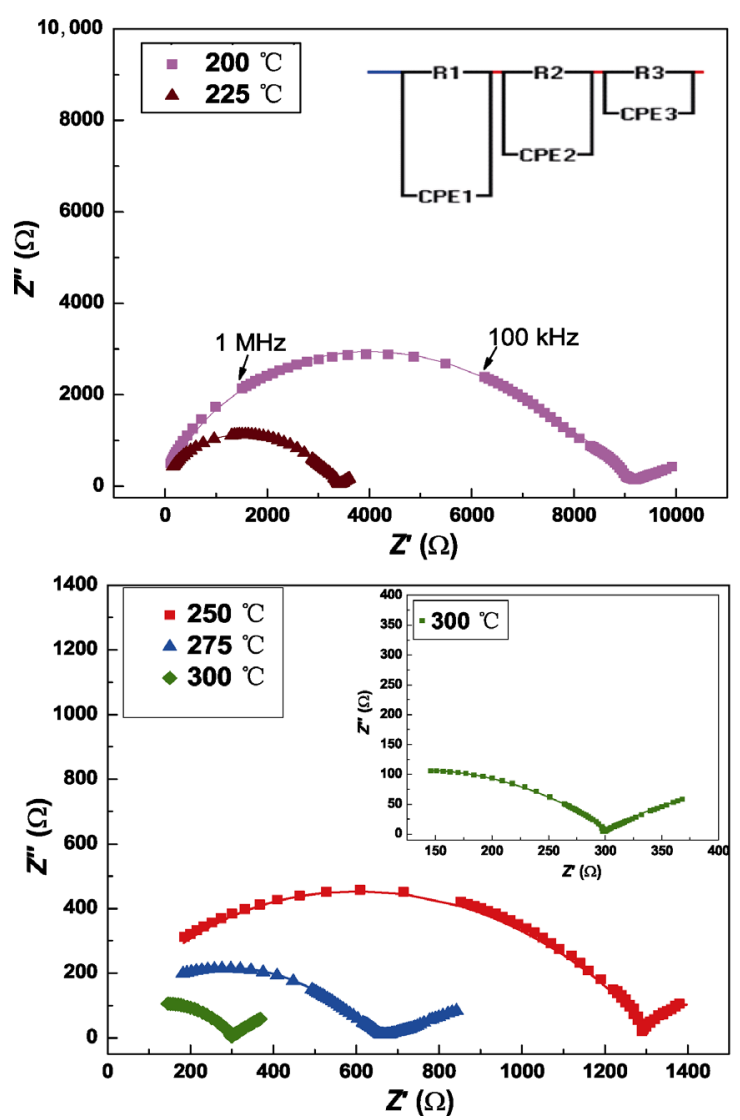

Fig. 7 Complex impedance plane plots of $x=0.175$ at 200-300 ${ }^{\circ} \mathrm{C}$. Note: The solid line shows the fitted data.

software [42], with an equivalent circuit using depressed semicircle model. The relative error of the fitted spectrum from the experimental data was $<2 \%$. The equivalent circuit used, can be described as a series combination of three parallel resistance and constant phase element (CPE) (shown in the inset of Fig. 6), 
where R1 and CPE1, R2 and CPE2 correspond to the contribution of grain and grain boundary, respectively. The values of circuit parameters extracted from fitting and the various electrical parameters then obtained are presented in Table 5 .

The true capacitance was estimated from CPE [13], and the values of grain capacitance $\left(C_{\mathrm{g}}\right)$ and grain boundary capacitance $\left(C_{\mathrm{gb}}\right)$ are found to be in the range of $\mathrm{pF}$ and $\mathrm{nF}$, respectively. As can be observed from Table 5, the value of $C_{\mathrm{gb}}$ is almost $10^{2}$ times higher as compared to $C_{\mathrm{g}}$, which indicates charge accumulation at the grain boundary.

The grain and grain boundary (total) conductivities $\left(\sigma_{\mathrm{g}}\right.$ and $\left.\sigma_{\mathrm{gbTot}}\right)$ were calculated from the pellet dimension, grain, and grain boundary resistance $\left(R_{\mathrm{g}}\right.$ and $R_{\mathrm{gb}}$ obtained from the fitting). However, the specific grain boundary conductivity $\left(\sigma_{\text {gbsp }}\right)$ is calculated with 'Brick layer model' [43,44], according to

$$
\frac{C_{\mathrm{g}}}{C_{\mathrm{gb}}}=\frac{\delta}{l_{\mathrm{g}}}
$$

where $\delta$ is the grain boundary width. Hence,

$$
\begin{aligned}
\sigma_{\mathrm{gbsp}} & =\left(\delta / l_{\mathrm{g}}\right)\left(\sigma_{\mathrm{gbTot}}\right)=\left(C_{\mathrm{g}} / C_{\mathrm{gb}}\right)\left(\sigma_{\mathrm{gbTot}}\right) \\
& =\left(\tau_{\mathrm{g}} / \tau_{\mathrm{gb}}\right)\left(\sigma_{\mathrm{g}}\right)
\end{aligned}
$$

where $\tau_{\mathrm{g}}\left(=C_{\mathrm{g}} R_{\mathrm{g}}\right)$ and $\tau_{\mathrm{g}}\left(=C_{\mathrm{gb}} R_{\mathrm{gb}}\right)$ are the grain and grain boundary relaxation time, respectively. As expected, an increase in temperature results in a decrease of both $R_{\mathrm{g}}$ and $R_{\mathrm{gb}}$ and for high temperature (in the given temperature range), overall resistance is dominated by the contribution of grain interior (Fig. 6). Consequently, with temperature, an increasing trend in conductivity ( $\sigma_{\mathrm{g}}, \sigma_{\mathrm{gbTot}}$, and $\left.\sigma_{\mathrm{gbsp}}\right)$ has been found and similarly, the dominance of grain interior conductivity over grain boundary has been observed in total ionic conductivity. Further as can be observed from Table 5, there is a significant decrease in $\tau_{\mathrm{g}}$ with an increase in temperature suggesting short range diffusions in the grain interiors [33].

Table 5 Equivalent circuit fitted parameters of $x=$ 0.175 at $200-300{ }^{\circ} \mathrm{C}$

\begin{tabular}{cccccccc}
\hline$T\left({ }^{\circ} \mathrm{C}\right)$ & $C_{\mathrm{g}}(\mathrm{pF})$ & $\begin{array}{l}\sigma_{\mathrm{g}} \times 10^{-4} \\
\left(\mathrm{~S} \cdot \mathrm{cm}^{-1}\right)\end{array}$ & $C_{\mathrm{gb}}(\mathrm{nF})$ & $\begin{array}{c}\sigma_{\mathrm{gbTot}} \times \\
10^{-3} \\
\left(\mathrm{~S} \cdot \mathrm{cm}^{-1}\right)\end{array}$ & $\begin{array}{c}\sigma_{\mathrm{gbsp}} \times \\
10^{-5} \\
\left(\mathrm{~S} \cdot \mathrm{cm}^{-1}\right)\end{array}$ & $\begin{array}{c}\tau_{\mathrm{g}} \times 10^{-7} \\
(\mathrm{~S})\end{array}$ & $\begin{array}{c}\mathrm{gb} \times 10^{-6} \\
(\mathrm{~S})\end{array}$ \\
\hline 200 & 67.07 & 0.28 & 7.00 & 0.17 & 0.16 & 5.15 & 9.24 \\
225 & 66.72 & 0.78 & 3.64 & 0.35 & 0.63 & 1.87 & 2.29 \\
250 & 65.70 & 1.95 & 3.23 & 1.13 & 2.31 & 0.73 & 0.62 \\
275 & 65.68 & 3.93 & 5.93 & 2.07 & 2.29 & 0.36 & 0.62 \\
300 & 66.00 & 8.70 & 3.03 & 4.46 & 9.71 & 0.17 & 0.15 \\
\hline
\end{tabular}

Arrhenius plots of ionic conductivity for all studied specimens are shown in Fig. 8. These conductivity plots show two regimes of linear extrapolation corresponding to the high and low temperature in which the activation energies of oxide ion motion were calculated. For lower substitution, $x=0.10$, a sharp discontinuity at $\sim 420{ }^{\circ} \mathrm{C}$ and a sharp increase in conductivity beyond $420{ }^{\circ} \mathrm{C}$ have been observed. This discontinuity indicates a transition from $\beta$-phase to $\gamma$-phase and the improvement in conductivity is due to the structural disorder in the crystal as a result of the phase transformation. For $x=0.15$, a subtle discontinuity was found showing the domination of the tetragonal phase at room temperature. But the ionic conductivity plots of $0.175 \leqslant x \leqslant 0.25$ without such discontinuities indicating suppression of the orthorhombic phase and room temperature stabilization of tetragonal phase. Moreover, the two regimes with a different activation energy $\left(E_{\mathrm{a}}\right)$ observed are for the order-disorder $\left(\gamma^{\prime}-\gamma\right)$ transition $[45,46]$. Muller et al. [26] explained this order-disorder transition in BICOVOX.15 system. In high temperature neutron thermodiffractometry analysis which revealed the expansion of $a$ - and $b$-parameters, contraction of $c$-parameter of the unit cell and a rapid increase in mean square atomic displacement $\left(d^{2}\right)$, resulted in modified diffusive phenomena in vanadate layers and decrease in activation energy, hence enhancement of ionic conductivity. In the intermediate temperature range, initially with substitution, the ionic conductivity was found to be increased up to $x=0.175$. Further addition of $\mathrm{Al}$ and $\mathrm{Ti}$ amount resulted in a decrease in ionic conductivity which may be due to the trapping of

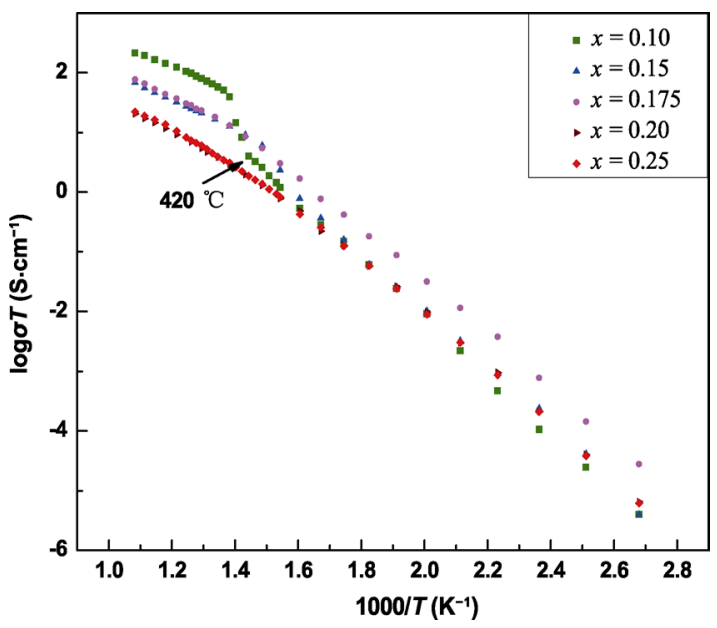

Fig. 8 Temperature dependence of conductivity for different dopant concentrations. 
mobile charge carriers because of defect pair formation $[22,23]$. This can be also correlated with the traces of impurities observed in these compositions through SEM as substitution goes beyond the solubility limit. At $300{ }^{\circ} \mathrm{C}$, the highest ionic conductivity was obtained for $x=0.175$, i.e., $7.28 \times 10^{-4} \mathrm{~S} \cdot \mathrm{cm}^{-1}$. This enhancement in the ionic conductivity as compared to parent compound as well as single doped Al compound [21-23] at an intermediate temperature range is due to near complete room temperature stabilization of fully disordered tetragonal phase. Simultaneous doping of aliovalent dopants $\mathrm{Al}$ and $\mathrm{Ti}$ appears to be effective for creation of more oxygen vacancies (charge carrier), as coinfirmed from UV-Vis study, that assists the oxide ion mobility as well as substitutional vacancy disordering in the crystal structure, is also the reason for rapid diffusion and consequent high ionic conductivity in this composition. Moreover, as observed in SEM, low porosity, the well developed and proper sized grain due to grain growth is also a cause. In polycrystalline compounds, the increase of grain size often decreases the grain boundary contribution to the resistivity and thus, favours the oxygen vacancy transport. In addition to this, the highest ionic conductivity of $x=0.175$ specimen is in accordance with the observed lowest activation energy of conduction, Hence, $x=0.175$ is found to be the optimum composition in the present system for maximum ionic conductivity.

In the high-temperature regime, at $600{ }^{\circ} \mathrm{C}$, the highest ionic conductivity of $1.89 \times 10^{-1} \mathrm{~S} \cdot \mathrm{cm}^{-1}$ is obtained for $x=0.1$. Further substitution results in an increase in activation energy and a decrease in the value of ionic conductivity. It is because the dopant cations, ME (Ti/Al), prefer either tetrahedral or octahedral coordination unlike vanadium which can have variable coordination states, due to which in the oxygen environment of vanadate layer ratio of vanadium polyhedral varies with variation of V/ME and reduction of vanadium results in defect trapping $[47,48]$. Hence, mostly in BIMEVOX system, it has been found that substitution of ME dopants results in enhancement of the conductivity in intermediate temperature range, but not in high-temperature range.

\section{Conclusions}

The influence of simultaneous doping of $\mathrm{Al}$ and $\mathrm{Ti}$ on the phase formation and ionic conductivity of bismuth vanadate $\left(\mathrm{Bi}_{2} \mathrm{VO}_{5.5-\delta}\right)$ has been studied by varying substitution amount. XRD study revealed the dominance of the tetragonal phase in the composition for $x=0.15$ but close to complete tetragonal phase occurs for $x \geqslant$ 0.175 . This is in confirmative with DSC result that shows suppression of $\beta \rightarrow \gamma$ phase transition for $x \geqslant$ 0.175 . For the highest amount substitution $x=0.25$, an impurity peak was noticed in XRD spectra indicating the presence of a second phase $\left(\mathrm{BiVO}_{4}\right)$, which was further supported by the observed substantial traces of impurities in SEM micrograph. Impedance spectroscopy measurements revealed the domination of grain interior contribution in the overall resistance. Notably, in the intermediate temperature range, all prepared compositions enhanced ionic conduction was observed as compared to the parent compound as well as BIALVOX system at the same temperatures. This can be ascribed to the occurrence of more oxygen vacancies and high crystallographic disordering facilitated by aliovalent substitution. Moreover, for the $\mathrm{Bi}_{2} \mathrm{~V}_{0.825} \mathrm{Al}_{0.0875} \mathrm{Ti}_{0.0875} \mathrm{O}_{5.5-\delta}$, the maximum value of ionic conductivity was obtained and is related with the presence of comparatively higher order of oxygen ion vacancies as confirmed from UV-Vis analysis as well as may be additionally correlated with the grain growth phenomena observed in this composition.

\section{Acknowledgements}

The authors are aptly thankful to Department of Science \& Technology (DST), New Delhi for facilitating FIST facility in the Department of Physics (sanction order number SB/52/CMP-093/2013) for XRD and impedance studies. FT-IR facility extended by Tezpur University, SEM facility of CSIC, Dibrugarh University, and DSC facility of CIF, IIT Guwahati are gratefully acknowledged. Amarjyoti SAIKIA gratefully acknowledges DST, New Delhi for Innovation in Science Pursuit for Inspired Research (INSPIRE) fellowship (No. IF160767).

\section{References}

[1] Kharton VV, Naumovich EN, Yaremchenko AA, et al. Research on the electrochemistry of oxygen ion conductors in the former Soviet Union. J Solid State Electrochem 2001, 5: 160-187.

[2] Shantha K, Varma K. Frequency dependence of the dielectric properties of ferroelectric $\mathrm{Bi}_{2} \mathrm{VO}_{5.5}$ ceramics. Solid State Ionics 1997, 99: 225-231. 
[3] Löfberg A, Boujmiai S, Capoen E, et al. Oxygen permeation versus catalytic properties of bismuth-based oxide ion conductors used for propene oxidation in a catalytic dense membrane reactor. Catal Today 2004, 91: 79-83.

[4] Kumar SURENDER, Sahare PD. Photocatalytic activity of bismuth vanadate for the degradation of organic compounds. Nano 2013, 8: 1350007.

[5] Trzciński K, Borowska-Centkowska A, Sawczak M, et al. Photoelectrochemical properties of BIMEVOX $(\mathrm{ME}=\mathrm{Cu}$, $\mathrm{Zn}, \mathrm{Mn}$ ) electrodes in contact with aqueous electrolyte. Solid State Ionics 2015, 271: 63-68.

[6] Vannier RN, Pernot E, Anne M, et al. $\mathrm{Bi}_{4} \mathrm{~V}_{2} \mathrm{O}_{11}$ polymorph crystal structures related to their electrical properties. Solid State Ionics 2003, 157: 147-153.

[7] Abraham F, Debreuille-Gresse MF, Mairesse G, et al. Phase transitions and ionic conductivity in $\mathrm{Bi}_{4} \mathrm{~V}_{2} \mathrm{O}_{11}$ an oxide with a layered structure. Solid State Ionics 1988, 28: 529-532.

[8] Abraham F, Boivin J, Mairesse G, et al. The bimevox series: A new family of high performances oxide ion conductors. Solid State Ionics 1990, 40-41: 934-937.

[9] Vannier R, Mairesse G, Abraham F, et al. Thermal behaviour of $\mathrm{Bi}_{4} \mathrm{~V}_{2} \mathrm{O}_{11}$ : X-ray diffraction and impedance spectroscopy studies. Solid State Ionics 1995, 78: 183-189.

[10] Krok F, Abrahams I, Bangobango DG, et al. Electrical and structural study of BICOVOX. Solid State Ionics 1996, 86-88: 261-266.

[11] Krok F, Abrahams I, Bangobango D, et al. Structural and electrical characterisation of BINIVOX. Solid State Ionics 1998, 111: 37-43.

[12] Lazure S, Vernochet C, Vannier RN, et al. Composition dependence of oxide anion conduction in the BIMEVOX family. Solid State Ionics 1996, 90: 117-123.

[13] Tripathy D, Pandey A. Structural and impedance studies of TiIV and NbV co-doped bismuth vanadate system. $J$ Alloys Compd 2018, 737: 136-143.

[14] Paydar MH, Hadian AM, Fafilek G. Ionic conductivity and crystal structure relationships in $\mathrm{Ti} / \mathrm{Cu}$ substituted $\mathrm{Bi}_{4} \mathrm{~V}_{2} \mathrm{O}_{11}$. J Mater Sci 2004, 39: 1357-1361.

[15] Emel'yanova YV, Tsygankova EN, Petrova SA, et al. Synthesis, structure, and conduction of solid solutions BIMEVOX $(\mathrm{Me}=\mathrm{Cu}$, Ti). Russ $J$ Electrochem 2007, 43: 737-741.

[16] Velichko EV, Mikhailovskaya ZA, Morozova MV, et al. Synthesis, region of existence, structural characteristics, and conductivity of $\mathrm{BI}(\mathrm{CR}, \mathrm{FE}) \mathrm{VOX}$ solid solutions. Russ J Electrochem 2011, 47: 563-568.

[17] Tripathy D, Saikia A, Pandey A. Effect of simultaneous Ti and $\mathrm{Nb}$ doping on structure and ionic conductivity of $\mathrm{Bi}_{2} \mathrm{~V}_{1-x} \mathrm{Ti}_{x / 2} \mathrm{Nb}_{x / 2} \mathrm{O}_{5.5-\delta}(0.1 \leq x \leq 0.25)$ ceramics. Ionics 2019 , 25: 2221-2230.

[18] Lee CK, Ong CS. Synthesis and characterisation of rare earth substituted bismuth vanadate solid electrolytes. Solid
State Ionics 1999, 117: 301-310.

[19] Joubert O, Game M, Varmier RN, et al. Solid phase synthesis and characterization of new BIMEVOX series: $\mathrm{Bi}_{4} \mathrm{~V}_{2-x} \mathrm{M}_{x} \mathrm{O}_{11-x}(\mathrm{M}=\mathrm{CrIII}$, FeIII). Solid State Ionics 1996, 83: 199-207.

[20] Buyanova ES, Morozova MV, Emel'yanova YV, et al. Synthesis, structure, and conductivity of BINBVOX ceramics. Russ J Inorg Chem 2013, 58: 259-264.

[21] Lee CK, Bay BH, West AR. New oxide ion conducting solid electrolytes, $\mathrm{Bi}_{4} \mathrm{~V}_{2} \mathrm{O}_{11}: \mathrm{M} ; \mathrm{M}=\mathrm{B}, \mathrm{Al}, \mathrm{Cr}$, Y, La. $J$ Mater Chem 1996, 6: 331.

[22] Beg S, Al-Alas A, Al-Areqi NAS. Layered Aurivillius compound: Synthesis, characterization and electrical properties. J Alloys Compd 2010, 504: 413-419.

[23] Kant R, Singh K, Pandey O. Synthesis and characterization of bismuth vanadate electrolyte material with aluminium doping for SOFC application. Int J Hydrog Energy 2008, 33: 455-462.

[24] Match!-phase identification from powder diffractionVersion 3, crystal impact. H. Putz, K. Brandenburg GbR, Kreuzherrenstr. 102, 53227 Bonn, Germany.

[25] Sooryanarayana K, Row TNG, Varma KBR. Structural phase transitions in $\mathrm{Bi}_{2} \mathrm{~V}_{1-x} \mathrm{Ge}_{x} \mathrm{O}_{5.5-x / 2}(x=0.2,0.4$, and 0.6) single crystals: X-ray crystallographic study. Mater Res Bull 1999, 34: 425-432.

[26] Muller C, Anne M, Bacmann M. Lattice vibrations and order-disorder transition in the oxide anion conductor BICOVOX.15: A neutron thermodiffractometry study. Solid State Ionics 1998, 111: 27-36.

[27] Kant R, Singh K, Pandey OP. Structural, thermal and transport properties of $\mathrm{Bi}_{4} \mathrm{~V}_{2-x} \mathrm{Ga}_{x} \mathrm{O}_{11-\delta}(0 \leqslant x \leqslant 0.4)$. Ionics 2010, 16: 277-282.

[28] Khaerudini DS, Guan G, Zhang P, et al. Oxide ion conductors based on niobium-doped bismuth vanadate: Conductivity and phase transition features. Ionics 2016, 22: 93-97.

[29] Krok F, Abrahams I, Malys M, et al. Structural and electrical consequences of high dopant levels in the BIMGVOX system. Solid State Ionics 2000, 136: 119-125.

[30] Yan J, Greenblatt M. Ionic conductivities of solid solutions. Solid State Ionics 1995, 81: 225-233.

[31] Alga M, Ammar A, Essalim R, et al. Synthesis, sintering and electrical properties of $\mathrm{P}$-doped $\mathrm{Bi}_{4} \mathrm{~V}_{2} \mathrm{O}_{11}$ ceramics. Solid State Sci 2005, 7: 1173-1179.

[32] Buyanova ES, Morozova MV, Emelyanova JV, et al. Structure, thermal stability and electrical conductivity of BINBVOX. Solid State Ionics 2013, 243: 8-17.

[33] Beg S, Al-Areqi NAS, Al-Alas A, et al. Influence of dopant concentration on the phase transition and ionic conductivity in BIHFVOX system. Phys B Condens Matter 2009, 404: 2072-2079.

[34] Tauc J, Grigorovici R, Vancu A. Optical properties and electronic structure of amorphous germanium. Phys Stat Sol (b) 1966, 15: 627-637.

[35] Davis EA, Mott NF. Conduction in non-crystalline systems 
V. Conductivity, optical absorption and photoconductivity in amorphous semiconductors. Philos Mag 1970, 22: 0903-0922.

[36] Mott NF, Davis EA. Electronic Processes in Non-Crystalline Materials, 2nd edn. Oxford and New York: Clarendon Press, 1979.

[37] Kaur G, Pickrell G, Kumar V, et al. Optical, mechanical and TEM assessment of titania-doped $\mathrm{Bi}_{2} \mathrm{~V}_{1-x} \mathrm{Ti}_{x} \mathrm{O}_{5.5-\delta}$ bismuth vanadate oxides. Bull Mater Sci 2014, 37: 1647-1656.

[38] Jiang ZY, Liu YY, Li MM, et al. One-pot solvothermal synthesis of $\mathrm{Bi}_{4} \mathrm{~V}_{2} \mathrm{O}_{11}$ as $\mathrm{A}$ new solar water oxidation photocatalyst. Sci Rep 2016, 6: 22727.

[39] Kumar S, Sahare PD. Photocatalytic activity of bismuth vanadate for the degradation of organic compounds. Nano 2013, 8: 1350007.

[40] Bag S, Behera B. Structural, micro-structural and electrical properties of rare earth doped $\mathrm{Bi}_{4} \mathrm{~V}_{2} \mathrm{O}_{11}$ Ceramics. ECS $J$ Solid State Sci Technol 2017, 6: N127-N136.

[41] Bag S, Das P, Behera B. AC impedance spectroscopy and conductivity studies of Dy doped $\mathrm{Bi}_{4} \mathrm{~V}_{2} \mathrm{O}_{11}$ ceramics. $J$ Theor Appl Phys 2017, 11: 13-25.

[42] Bondarenko AS, Ragoish GA. In Progress in Chemometrics Research. Pomerantsev AL, Ed. New York: Nova Science Publishers, 2005: 89-102

[43] Bowman WJ, Zhu JT, Sharma R, et al. Electrical conductivity and grain boundary composition of Gd-doped and $\mathrm{Gd} / \mathrm{Pr}$ co-doped ceria. Solid State Ionics 2015, 272: 9-17.

[44] Martin M. Grain boundary ionic conductivity of yttrium stabilized zirconia as a function of silica content and grain size. Solid State Ionics 2003, 161: 67-79.

[45] Kežionis A, Bogusz W, Krok F, et al. Relaxation dispersion of ionic conductivity of BICOVOX. Solid State Ionics 1999, 119: $145-150$

[46] Abrahams I, Krok F, Malys M, et al. Phase transition studies in BIMEVOX solid electrolytes using AC impedance spectroscopy. Solid State Ionics 2005, 176: 2053-2058.

[47] Tripathy D, Saikia A, Tado GT, et al. Dielectric study of Ti-doped $\mathrm{Bi}_{2} \mathrm{VO}_{5.5}$ solid electrolyte. Indian J Phys 2019, 93: 845-859.

[48] Abrahams I, Krok F, Malys M, et al. Defect structure and ionic conductivity as a function of thermal history in BIMGVOX solid electrolytes. J Mater Sci 2001, 36: 1099-1104.

Open Access This article is licensed under a Creative Commons Attribution 4.0 International License, which permits use, sharing, adaptation, distribution and reproduction in any medium or format, as long as you give appropriate credit to the original author(s) and the source, provide a link to the Creative Commons licence, and indicate if changes were made.

The images or other third party material in this article are included in the article's Creative Commons licence, unless indicated otherwise in a credit line to the material. If material is not included in the article's Creative Commons licence and your intended use is not permitted by statutory regulation or exceeds the permitted use, you will need to obtain permission directly from the copyright holder.

To view a copy of this licence, visit http://creativecommons. org/licenses/by/4.0/. 